\title{
Global transcriptional profiling of the postmortem brain of a patient with G114V genetic Creutzfeldt-Jakob disease
}

\author{
CHAN TIAN $^{1 *}$, DI LIU $^{2 *}$, CHEN CHEN $^{3}$, YIN XU $^{1}$, HAN-SHI GONG $^{1,4}$, CAO CHEN $^{1}$, \\ QI SHI ${ }^{1}$, BAO-YUN ZHANG ${ }^{1}$, JUN HAN ${ }^{1}$ and XIAO-PING DONG ${ }^{1}$
}

\begin{abstract}
${ }^{1}$ State Key Laboratory for Infectious Disease Prevention and Control, National Institute for Viral Disease Control and Prevention, Chinese Center for Disease Control and Prevention, Beijing $102206 ;{ }^{2}$ Network Information Center, Institute of Microbiology, Chinese Academy of Sciences, Beijing 100101; ${ }^{3}$ State Key Laboratory for Infectious Disease Prevention and Control, National Institute for Communicable Disease Control and Prevention, Chinese Center for Disease Control and Prevention, Beijing 102206; ${ }^{4}$ School of Medicine, Xi'an Jiao Tong University, Xi'an, Shaanxi 710061, P.R. China
\end{abstract}

Received October 22, 2012; Accepted December 18, 2012

DOI: $10.3892 /$ ijmm.2013.1239

\begin{abstract}
Familial or genetic Creutzfeldt-Jakob disease (fCJD or gCJD) is an inherent human prion disease caused by mutation of the prion protein gene $(P R N P)$. In the present study, global expression patterns of the parietal cortex from a patient with G114V gCJD were analyzed using the Affymetrix Human Genome U133+ 2.0 chip with a commercial normal human parietal cortex RNA pool as a normal control. In total, 8,774 genes showed differential expression; among them 2,769 genes were upregulated and 6,005 genes were downregulated. The reliability of the results was confirmed using real-time RT-PCR assays. The most differentially expressed genes (DEGs) were involved in transcription regulation, ion transport, transcription, cell adhesion, and signal transduction. The genes associated with gliosis were upregulated and the genes marked for neurons were downregulated, while the transcription of the PRNP gene remained unaltered. A total of 169 different pathways exhibited significant changes in the brain of G114V gCJD. The most significantly regulated pathways included Alzheimer's and Parkinson's disease, oxidative phosphorylation, regulation of actin cytoskeleton, MAPK signaling and proteasome, which have previously been linked to prion diseases. In addition, we found some pathways that have rarely been explored in regards to prion diseases that were also significantly altered in G114V gCJD, such as axon
\end{abstract}

Correspondence to: Professor Xiao-Ping Dong, State Key Laboratory for Infectious Disease Prevention and Control, National Institute for Viral Disease Control and Prevention, Chinese Center for Disease Control and Prevention, 155 Chang-Bai Road, Beijing 102206, P.R. China

E-mail: dongxp238@sina.com

*Contributed equally

Key words: Creutzfeldt-Jakob disease, familial Creutzfeldt-Jakob disease, gene chip, expression pattern, microarray guidance, gap junction and purine metabolism. The majority of the genes in the 10 most altered pathways were downregulated. The data of the present study provide useful insights into the pathogenesis of G114V gCJD and potential biomarkers for diagnostic and therapeutic purposes.

\section{Introduction}

Prion diseases, also known as transmissible spongiform encephalopathies (TSEs), are a group of fatal neurodegenerative disorders in humans and animals, including Creutzfeldt-Jakob disease (CJD) in humans, bovine spongiform encephalopathies (BSEs) in cattle, and scrapie in sheep and goats. The conversion of prion protein (PrP), coded by the PRNP gene, from its cellular isoform $\mathrm{PrP}^{\mathrm{C}}$ to its pathogenic isoform $\mathrm{PrP}^{\mathrm{Sc}}$ through a post-translational process is considered the etiology of these diseases. As a result of the conversion, the portion of $\beta$-sheets within PrP is increased (from 3 to $45 \%$ ) whereas that of $\alpha$-helices decreases (from 42 to $30 \%$ ), therefore causing PrP to become detergent insoluble and resistant to denaturant (isoform $\mathrm{PrP}^{\mathrm{Sc}}$ ) (1). The conversion also causes a series of histopathological changes, including the depositions of $\mathrm{PrP}^{\mathrm{Sc}}$, spongiform degenerations, neuronal loss and astrogliosis.

According to the pathomechanisms, CJD can be classified into sporadic CJD (sCJD), familial or genetic CJD (fCJD or gCJD) and iatrogenic CJD (iCJD). fCJD accounts for approximately $10-15 \%$ of all CJD cases, characterized by the genetic changes of PrP (2). To date, 56 different mutations, including residue substitutions, insertions and deletions, have been reported (3). For instance, proline to leucine mutation at the 102nd position (P102L) causes Gerstmann-StrausslerScheinker syndrome (GSS) characterized by the impairment of cerebellum (4). Nevertheless, D178N leads to fatal familial insomnia (FFI) (4), mainly harming the thalamus region. The varied clinical manifestations indicate that different mutants may trigger different regulatory pathways.

An efficient approach to uncovering the regulated genes and the signaling pathways caused by $\mathrm{PrP}^{\mathrm{Sc}}$ is using global transcriptional profiling on prion-infected samples. Studies on various prion strains in mice by Hwang et al (5) described a 
network of differentially expressed genes (DEGs) on functional pathways and discovered that the gliosis fibril acidic protein gene (Gfap) and a set of complement activation associated genes are highly expressed (5). Xiang et al (6) performed their studies using human SCJD brains and described the upregulation of immune and stress-response factors and elements involved in cell death and cell cycle, and the downregulation of genes encoding synaptic proteins (6). However, there is a lack of information on the global transcriptional profiles of gCJD patients, since gCJD and sCJD may utilize different regulatory mechanisms.

In our previous study, we reported a Chinese gCJD patient with a G114V mutation in $\operatorname{PrP}(7)$, showing an sCJD-like neuropathological abnormality with large amounts of $\mathrm{PrP}^{\mathrm{Sc}}$ deposit, spongiform degeneration, astrogliosis and neuron loss in the cortex regions (8). To further investigate the molecular mechanisms and to compare those with SCJD, the full transcriptome pattern of the parietal cortex lobe of this G114V gCJD patient was profiled with microarray analysis (Affymetrix Human Genome U133+ 2.0 Chip) with a commercial normal human parietal cortex RNA pool as control. This investigation revealed numerous DEGs and pathways and our results provide information regarding gCJD that is useful for the development of novel diagnostic and therapeutic approaches.

\section{Materials and methods}

Brain sample of the G114V fCJD patient. Brain tissue of the parietal cortex obtained from a patient definitely diagnosed with G114V gCJD was enrolled in this study. The patient was a 47-year-old (at onset) Han-Chinese woman, whose clinical and genetic characteristics have previously been described (7). Neuropathological assays of 10 different brain regions revealed typical sCJD-like abnormality and $\mathrm{PrP}^{\mathrm{Sc}}$ deposits (8). A commercial normal human parietal cortex total RNA (cat. \#636571; Clontech) pooled from four males/females aged 35-89 years was utilized as a control. Usage of the stored human brain samples in this study was approved by the Ethics Committee of the National Institute for Viral Disease Prevention and Control, China CDC. We obtained written informed consent from all participants in our study.

Microarray analysis. Total RNA of the parietal cortex of the patient with G114V gCJD was extracted with an RNeasy Mini kit (cat. \#74104; Qiagen), according to the manufacturer's instructions. The quality and quantity of extracted RNAs were verified by $1.2 \%$ formaldehyde agarose electrophoresis and ultraviolet spectrophotometry (NanoDrop, ND-1000). The processes of labeling, hybridization and scanning were performed at a platform of CapitalBio Corporation. Briefly, $200 \mathrm{ng}$ of each total RNA preparation was taken for synthesis and amplification of first strand cDNAs, double-stranded cDNAs and biotin-labeled antisense RNAs, using a Message Amp ${ }^{\mathrm{TM}}$ Premier RNA Amplification kit (cat. \#AM1792; Ambion) on a PCR apparatus (MJ, PTC-225). After measuring the concentrations of the labeled RNAs by ultraviolet spectrophotometry, $15 \mu \mathrm{g}$ of each preparation was fragmented and verified using $1.2 \%$ formaldehyde denatured agarose electrophoresis.

The biotinylated cRNAs were hybridized to a commercial gene chip, GeneChip ${ }^{\circledR}$ Human Genome U133+ 2.0 (Affymetrix
Inc., Santa Clara, CA, USA) containing 47,000 transcripts, at $45^{\circ} \mathrm{C}$ for $16 \mathrm{~h}$ with constant rotation at a speed of $60 \mathrm{rpm}$. After washing and staining automatically on an Affymetrix fluidics station 450 with a GeneChip Hybridization, Wash and Stain kit (cat. \#900720; Affymetrix), the chips were then scanned on Affymetrix scanners $30007 \mathrm{G}$.

After scanning the gene chips, the CEL images were processed using the Affymetrix GCOS 1.4 software. The generated documents were analyzed according to the 'Affymetrix Statistical Algorithms Description Document'. Briefly, the raw data were subjected to processes including masking unusable data, background subtraction, probe values calculation, scaling, single chip analysis, and calculation of $\mathrm{P}$-value. A probe-set was considered as expressed if the corresponding detection P-value was $<0.04$. Genes were considered to be differentially expressed if their ratio (patient/control) was higher or lower than 2-fold.

The gene functions were formatted for both gene ontologies (GO) and molecular function (9). The GO and molecular functions of the genes with 6-fold differential expression compared to controls were further analyzed by CapitalBio ${ }^{\circledR}$ Molecule Annotation System V3.0 (MAS3.0) (http://bioinfo. capitalbio.com/mas3/). The P-value was calculated according to a probability formula of hypergeometric distribution, reflecting the importance of the selected pathway or GO. The smaller the P-value, the higher its significance. The pathways were ranked in the order of P-value and the 10 most important ones were chosen for further analyses. Meanwhile, a Q-value corresponding to the P-value was calculated to evaluate the false discovery rate (FDR) of significant pathway and GO through screening by using a single P-value as cut-off. The smaller the Q-value, the lower the FDR.

All data are MIAME compliant and the raw data have been deposited in the GEO database (10) with the accession number of that, platform of GPL570, samples of GSM759883 and GSM759884, as well as series of GSE30643.

Quantitative RT-PCR ( $q R T-P C R)$. Prior to qRT-PCR, the RNA extracts were treated with a commercial RQ1 RNase-Free DNase (cat. \#M6101; Promega) for $1 \mathrm{~h}$ at $37^{\circ} \mathrm{C}$ according to the manufacturer's instructions. For cDNA synthesis, $2 \mu \mathrm{g}$ of treated RNAs were mixed with the reagents in Reverse Transcription System (cat. \#A3500; Promega). The real-time PCR was carried out on an ABI Prism 7900 sequencing detector, at the conditions of denaturing at $95^{\circ} \mathrm{C}$ for $15 \mathrm{sec}$, annealing at $50^{\circ} \mathrm{C}$ for $2 \mathrm{~min}$ and extension at $62^{\circ} \mathrm{C}$ for $1 \mathrm{~min}, 40$ cycles in total. $\beta$-actin gene was used as an internal control to normalize the expression levels of target mRNAs. The primers for each gene are shown in Table I.

\section{Results}

Global transcriptional profiling of the G114V gCJD patient. Following our previous studies on the G114V gCJD patient $(7,8)$, we further investigated all the transcriptional patterns of the brain sample and compared them to those of normal brain RNA pool (control). To better understand the expression level of screened genes, we ranked them with the relative difference ratio using the following strategy: after single chip normalization, each probe set was marked as present $(\mathrm{P})$ or absent $(\mathrm{A})$ 
Table I. Primers used for the real-time RT-PCR target genes.

\begin{tabular}{llllc}
\hline & Gene ID & \multicolumn{1}{c}{ Sense primer } & \multicolumn{1}{c}{ Antisense primer } & $\begin{array}{c}\text { Product } \\
\text { length (bp) }\end{array}$ \\
\hline Decreased genes & PHLDA2 & ACAGCCTCTTCCAGCTATGG & GGTGGTGACGATGGTGAA & 173 \\
& HBB & ACGTGGATGAAGTTGGTGGT & CTCACTCAGTGTGGCAAAGGT & 215 \\
& NR4A2 & ACCACTCTTCGGGAGAATACAG & ACAGGGGCATTTGGTACAAG & 180 \\
& CBLN4 & CTGGGCACAGAACGACAC & AAGGCGACCTTGGAGTTG & 144 \\
Increased genes & ZNF396 & TGGAAGAGGAAGAGCAGACC & CCTCAGCCAGAGATGACAAAG & 167 \\
& ZNF292 & GAGCAGGAGAGGTTGAGTTG & AGATAAGGTCGGGCTTAACA & 257 \\
& EIF5B & GACAGCACCAAGGATGACATT & GTTTTCTGTTGGCTTCACTGC & 228 \\
& UBE3A & GAGCAGCTGCAAAGCATCTA & CTTTCTTGGAGGGATGAGGAT & 195 \\
\hline
\end{tabular}

Table II. Significantly altered biological processes of gene ontology.

\begin{tabular}{|c|c|c|c|c|}
\hline GO term & Count & P-value & Q-value & 5 most up and downregulated genes, respectively \\
\hline $\begin{array}{l}\text { GO: } 0006355 \text { regulation of } \\
\text { transcription, DNA-dependent }\end{array}$ & 114 & $3.62 \mathrm{E}-72$ & $2.60 \mathrm{E}-70$ & $\begin{array}{l}\text { ATRX, CHD9, ZNF292, ZNF396, JMJD1C; } \\
\text { ZNF200, MEF2C, TBC1D9, ZMYM2, NR4A2 }\end{array}$ \\
\hline GO:0007165 signal transduction & 110 & $1.20 \mathrm{E}-49$ & $6.34 \mathrm{E}-48$ & $\begin{array}{l}\text { SYCP2, CPLX2, SLC5A3, GABRG1, BPTF; } \\
\text { SLC8A1, GRIN2A, ATP6V1B2, GRIN2A, GRIA4 }\end{array}$ \\
\hline GO:0006350 transcription & 106 & $3.72 \mathrm{E}-60$ & $2.18 \mathrm{E}-58$ & $\begin{array}{l}\text { PHF3, CHD9, ZNF292, ZNF396, JMJD1C; } \\
\text { ZNF200, BRWD1, MEF2C, ZMYM2, NR4A2 }\end{array}$ \\
\hline GO:0007275 development & 71 & $2.16 \mathrm{E}-31$ & $6.11 \mathrm{E}-30$ & $\begin{array}{l}\text { CSPP1, COL27A1, APC, TRAPPC2L, CD47; } \\
\text { PCDHA1, PCDH8, CD164, UCHL1, NELL1 }\end{array}$ \\
\hline GO:0006810 transport & 71 & $7.25 \mathrm{E}-29$ & $1.94 \mathrm{E}-27$ & $\begin{array}{l}\text { RNF130, DTNA, IL1RL1, PKN2, IL6ST; } \\
R T N 1, U C H L 1, P E N K, \text { OR2L13, NR4A2 }\end{array}$ \\
\hline GO:0006811 ion transport & 68 & $3.08 \mathrm{E}-62$ & $2.03 \mathrm{E}-60$ & $\begin{array}{l}\text { TIMM8A, VEGFA, NAV1, MPPED2, FOSL2; } \\
\text { ITM2B, FGF13, UCHL1, NELL1, GAP43 }\end{array}$ \\
\hline GO:0007155 cell adhesion & 67 & $3.29 \mathrm{E}-59$ & $1.86 \mathrm{E}-57$ & $\begin{array}{l}\text { ASPH, JMJD1C, SYCP2, CPLX2, PLOD2; } \\
\text { PCYOX1, VAT1L, SQLE, KCNAB1, SRD5A1 }\end{array}$ \\
\hline $\begin{array}{l}\text { GO:0007399 nervous } \\
\text { system development }\end{array}$ & 57 & $5.56 \mathrm{E}-45$ & $2.66 \mathrm{E}-43$ & $\begin{array}{l}\text { ASPH, JMJD1C, SYCP2, CPLX2, PLOD2; } \\
\text { PCYOX1, VAT1L, SQLE, KCNAB1, SRD5A1 }\end{array}$ \\
\hline GO:0015031 protein transport & 53 & $5.92 \mathrm{E}-42$ & $2.68 \mathrm{E}-40$ & $\begin{array}{l}\text { TIMM8A, CEP290, RASEF, RASEF, HSP90B1; } \\
A R F 4, N S F, C A D P S, C A D P S, C A D P S\end{array}$ \\
\hline GO:0008152 metabolism & 51 & 0.06 & 0.04 & $\begin{array}{l}\text { SFRS8, THOC2, PPIG, PRPF40A, ZRANB2; } \\
M A G O H, L S M 8, T H O C 4, \text { SRPK2, RBM9 }\end{array}$ \\
\hline GO:0008150 biological_process & 50 & 1.00 & 0.58 & $\begin{array}{l}\text { GABRG1, SYN2, CTNNB1, MAPK12, MAPK11; } \\
\text { TAC1, SYT1, SYN2, SNAP25, SLC1A6 }\end{array}$ \\
\hline
\end{tabular}

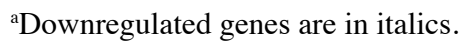

according to the comparison to background noise. Probe sets marked with $\mathrm{A}$ in both the experimental sample and control were discarded. Thus, we found the differentially expressed genes based upon two criteria, i) present in sample but absent in another sample, or ii) with the gene expression level altered over 2-fold. The genes that met both conditions were considered DEGs. After purging the redundant probe sets reflecting same genes, a total of 8,774 genes were determined to be differentially expressed in G114V gCJD brains. Among them, nearly one-third $(2,769)$ was upregulated and two-thirds $(6,005)$ were downregulated. Due to the lack of sufficient sample/data from other gCJD patients, we were unable to make parallel experiments/comparisons to minimize the gene set of gCJD specific genes. Furthermore, we did not use data from sCJD (6) or prion-infected mice (5), as the different molecular background may have induced unpredictable bias.

According to the annotations of Affy-Chip, 8,494 of the 8,774 genes were either assigned biological functions or were 
similar to genes with known functions, and 280 genes remain annotated as encoding hypothetical proteins. GO assignment determined these DEGs to be involved in 1,552 biological processes, with 819 molecular functions, and to be located in 368 cell components. In view of the significantly altered biological processes, 87 contained $>10$ DEGs. The predominantly altered processes covered the major basic cellular functions, including regulation of transcription, signal transduction, development and transport, oxidation reduction and apoptosis (Table II). Regarding the molecular functions, most DEGs were related to molecular (protein, nucleotide, ion) binding/ interactions. The cellular component assignment showed that most functional genes were located in the membrane system (plasma membrane, mitochondria, endoplasmic reticulum). Since the sample was collected from the gCJD patient postmortem, the transcriptional profile represents the terminal stage of the infected brain.

Identification of the most DEGs. According to the microarray results, the most upregulated genes included UBE3A and RBBP6, which are involved in the ubiquitin protein degradation system, suggesting that the ubiquitin-dependent catabolic processes are essential in the gCJD patient. ASPH was the second most highly expressed gene that plays an important role in calcium homeostasis. It is well known that destruction of calcium homeostasis is common in neurodegenerative diseases (11). On the contrary, the most downregulated genes included genes involved in iron ion binding (HBB), transcriptional regulation (NR4A2), signal transduction (OR2L13) and cell skeleton formation (NEFL) (Table III).

To evaluate the microarray results, we performed realtime PCR, targeting some specific genes from the brain of the G114V gCJD patient and the control RNA pool from the normal brain. Real-time PCR showed that the transcriptional levels of the downregulated genes HBB, CBLN4, PHLDA2 and NR4A2 from the microarray were markedly lower than those of the normal control, particularly PHLDA2 and NR4A2, which were $>40$-fold decreased and consistent with the microarray result. The upregulated genes EIF5B, UBE3A, ZNF396 and ZNF292 in the microarray were also significantly higher than the control in real-time PCR assay, particularly EIF5B, UBE3A and ZNF396 showing a $>30$-fold increase (Fig. 1). These findings indicate that the results of the microarray are reliable.

Involvement of significant pathways in G114V gCJD. To examine the changes of cell signaling pathways in the brain cortex of the G114V gCJD patient, the genes expressed at least 6-fold higher or lower than that of normal control were subsequently analyzed with the CapitalBio ${ }^{\circledR}$ Molecule Annotation System V3.0 (MAS 3.0) using KEGG pathways (12). In total, 169 different pathways with significant difference in expression $(\mathrm{P}<0.05)$ were identified. Briefly, 82 pathways were involved in metabolism, 28 in human diseases, 19 in organismal systems, 16 in environmental information processing, 14 in genetic information processing and 10 in cellular processes, according to the KEGG classification of functional pathways.

The 10 most altered pathways ranked in the order of P-value are summarized in Table IV. Most of the genes in these path-

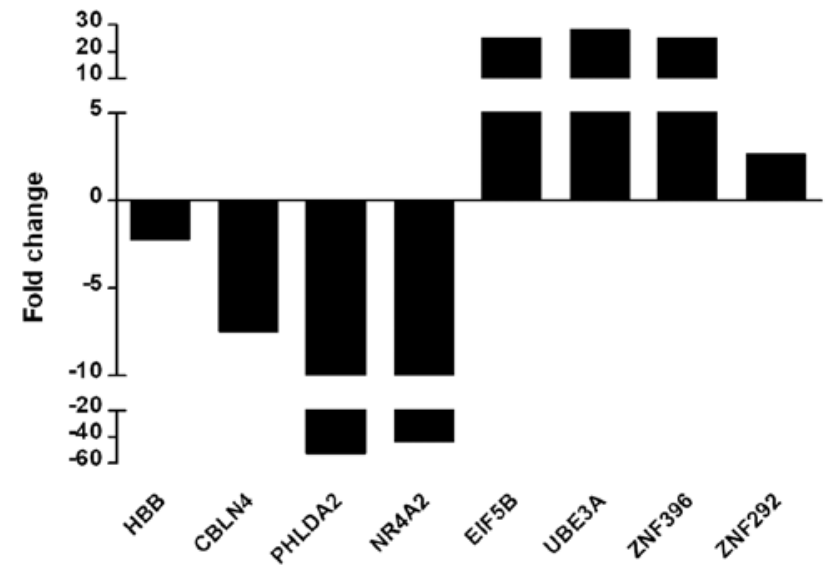

Figure 1. Confirmation of microarray results for the selected genes by realtime RT-PCR. Relative expression levels of the genes were indicated by the fold changes in expression level in G114V gCJD vs. control cases. The y-axis indicates fold changes and a negative value indicates downregulation.

ways were downregulated (Fig. 2). Notably, the first and the third most altered pathways were Alzheimer's disease (AD) and Parkinson's disease (PD). Within these two pathways, 31/34 genes and 27/28 genes were significantly downregulated in AD and PD pathways, respectively (Table IV). The downregulated genes related to these two pathways are involved in mitochondrial dysfunction, ER stress and apoptosis. These data suggest that G114V gCJD may share similar mechanisms to $\mathrm{AD}$ and $\mathrm{PD}$.

Genes related to oxidative phosphorylation and purine metabolism were also significantly altered. Out of 30 differentially altered genes of involved in oxidative phosphorylation, 29 were downregulated, including NADH dehydrogenase, succinate dehydrogenase, cytochrome $c$ reductase, cytochrome $c$ oxidase and F-type ATPase (Fig. 2). Regarding the purine metabolism pathway, all 24 altered genes were downregulated, including adenylosuccinate lyase, RNA polymerase II and some phosphodiesterases (Fig. 2). These observations indicate that there is a severe failure in the mitochondria and a severe dysfunction of cell metabolism at the terminal stage.

Two pathways related to the cytoskeleton were also markedly downregulated; 29/32 altered genes involved in the regulation of actin cytoskeleton were significantly downregulated. All 17 affected genes related to pathogenic Escherichia coli infection were downregulated; among them some gene products were cell structure proteins, i.e. CDC42 and tubulin. Additionally, other possible severely disrupted pathways included those related to gap junctions (17/20 DEGs downregulated), which are involved in direct communication between the cytosolic compartments of adjacent cells and the pathway of axon guidance (24/24 DEGs downregulated), which helps axons extend to their correct targets. The downregulation of these two pathways suggests that there is damage to cell communication and neuronal development in the G114V gCJD brain.

Among the 10 most affected pathways, the mitogenactivated protein kinase (MAPK) signaling pathway was the only one related to environmental signaling processing. The processes seemed to be markedly repressed as well, with 33/35 altered genes being downregulated, including kinases 


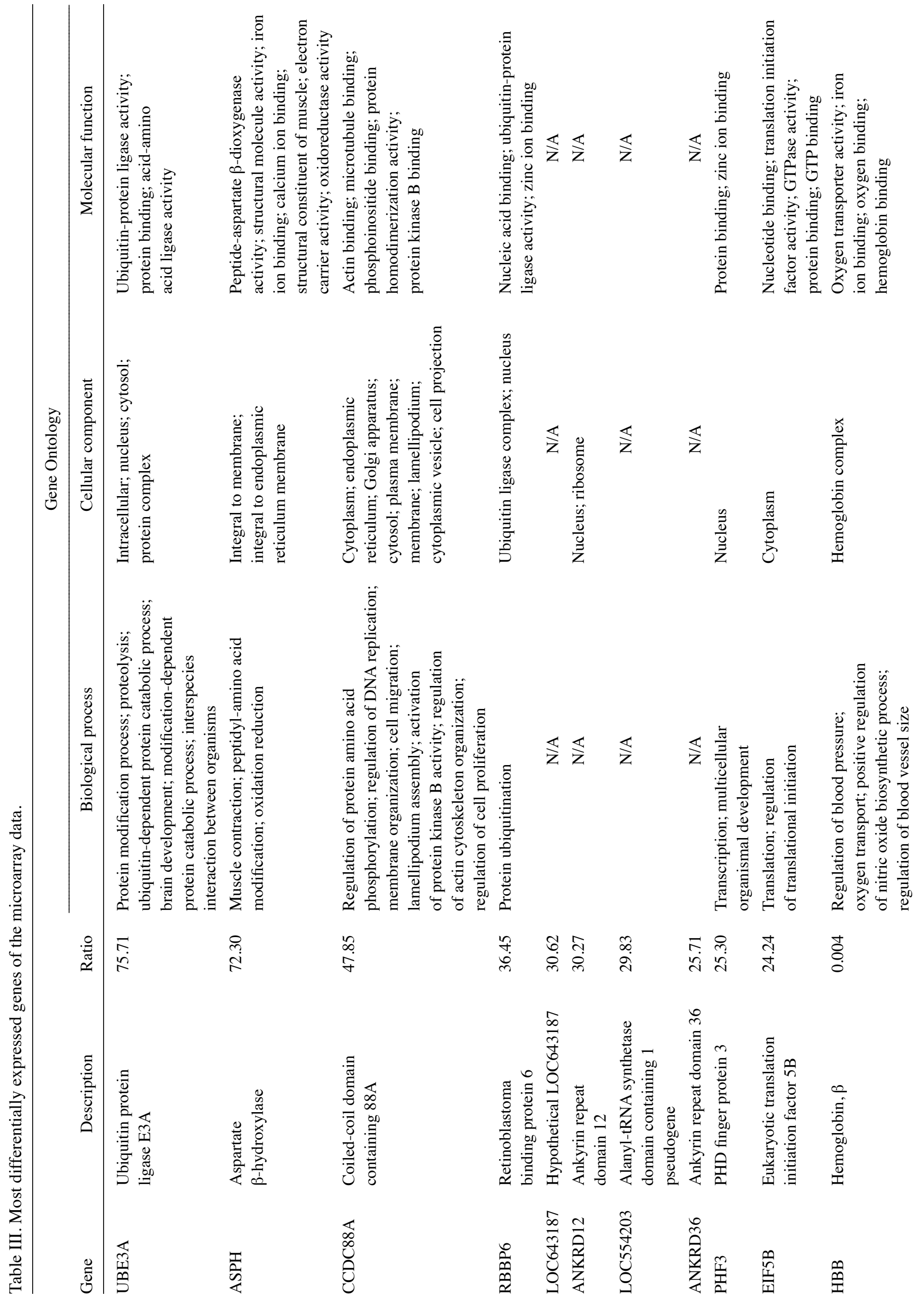




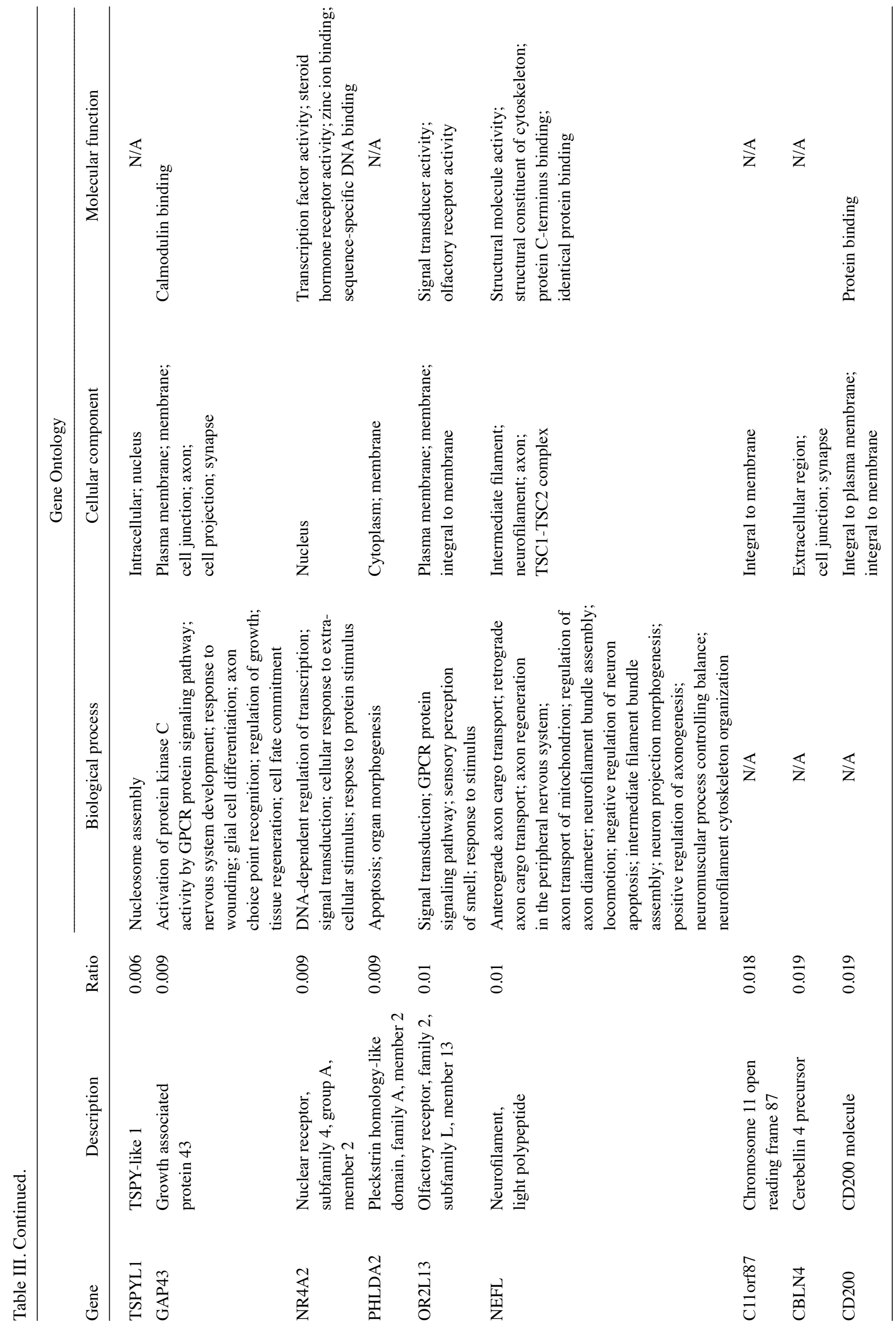


Table IV. The 10 most significantly regulated pathways deduced from the microarray data.

\begin{tabular}{lccc}
\hline Pathway & Count & P-value & Q-value \\
\hline Alzheimer's disease & 34 & $1.26 \mathrm{E}-17$ & $1.79 \mathrm{E}-16$ \\
Oxidative phosphorylation & 30 & $3.42 \mathrm{E}-17$ & $4.60 \mathrm{E}-16$ \\
Parkinson's disease & 28 & $1.40 \mathrm{E}-15$ & $1.47 \mathrm{E}-14$ \\
Regulation of actin cytoskeleton & 32 & $2.97 \mathrm{E}-13$ & $1.84 \mathrm{E}-12$ \\
Pathogenic Escherichia coli infection & 17 & $4.20 \mathrm{E}-13$ & $2.45 \mathrm{E}-12$ \\
MAPK signaling pathway & 35 & $1.67 \mathrm{E}-12$ & $8.40 \mathrm{E}-12$ \\
Axon guidance & 24 & $1.79 \mathrm{E}-12$ & $8.83 \mathrm{E}-12$ \\
Gap junction & 20 & $6.58 \mathrm{E}-12$ & $3.01 \mathrm{E}-11$ \\
Proteasome & 15 & $8.43 \mathrm{E}-12$ & $3.78 \mathrm{E}-11$ \\
Purine metabolism & 24 & $5.64 \mathrm{E}-11$ & $2.20 \mathrm{E}-10$ \\
\hline
\end{tabular}

(MAPK1, MAPK1, MAP2K1, MAP2K4, PRKCB, PAK1 and STK4), phosphatases (DUSP4, DUSP5, DUSP6, PPP3CA and $\mathrm{PPP} 3 \mathrm{CB}$ ) and some regulatory factors (FGF13, FGF14, MEF2C and RASGRF2) (Fig. 2). These genes were distributed in the three sub-pathways, classical MAP kinase pathway, JNK and p38 MAP kinase pathway, and extracellular-regulated kinase 5 (ERK5) pathway. This indicates that the local information processing in the brain of the gCJD patient was severely impaired.

The transcriptional pattern of important prion disease associated genes. Our previous study demonstrated large amounts of $\mathrm{PrP}^{\mathrm{Sc}}$ deposits and severe gliosis in the cortex regions of this G114V gCJD patient, while the transcription levels of $P R N P$ did not vary as much as in the $\mathrm{PrP}^{\mathrm{Sc}}$ deposit among 10 different regions (8). Furthermore, microarray data showed no difference in PRNP transcription between the patient's brain and normal control, even slightly downregulated in the patient's brain with several $P R N P$ probes, possibly indicating deposits of $\mathrm{PrP}^{\mathrm{sc}}$ in brains do not lead to enhancing the PRNP transcription. The transcriptional level of the GFAP gene in the patient was $\sim 2$-fold increased relative to that of the control, highlighting an active gliosis. Nevertheless, a spectrum of neuronal biomarkers was downregulated in the patient's brain, such as NSE (7.25-fold), tubulin- $\beta$ III (3.88-fold), MAP2 (8.13-fold), NF-M (38.46-fold), NF-H (12.35-fold) and NF subunit NF-L (27.78-fold), demonstrating severe neuron loss. These data are consistent with the pathological characteristics of G114V gCJD.

\section{Discussion}

In the present study, we analyzed the global expression patterns in the parietal cortex of a G114V gCJD patient with a commercial gene chip containing 47,000 transcripts. This is the highest-capacity approach to gene expression analysis used in human prion disease thus far. After purging the redundant transcripts, we identified 2,769 upregulated and 6,005 downregulated genes. Further qRT-PCRs for several differentially expressed genes confirmed the results of the microarray. Notably, more downregulated genes in the brain of G114V gCJD are consistent with the results of a previous study on sporadic CJD with a relatively lower throughput microarray (18,000 transcripts), in which 275 genes out of 287 differentially expressed genes were downregulated (6).

In line with the observations of the pathological abnormalities in the G114V gCJD patient $(8,13)$, the transcriptional level of the GFAP gene associated with gliosis is increased and a series of genes associated with neurons are decreased. Although the brain tissues are severely damaged pathologically, the expression levels of prion protein gene PRNP do not differ distinctly compared with those of normal control, which is in accordance not only with the data of PRNP transcription in this patient with qRT-PCR, but also with the previous microarray findings in the SCJD patients (6), mice infected with scrapie or CJD agents (14) and cattle infected with the BSE agent (15). Maintenance of active transcription of the PRNP gene in CNS tissues at the terminal stage of human and animal prion diseases may indicate a special environment that facilitates the replication of prion agents locally by supplying enough $\operatorname{PrP}^{\mathrm{C}}$ as the substrates for $\operatorname{PrP}^{\mathrm{Sc}}$ replication.

The most differentially expressed genes in G114V gCJD seem to be involved in multiple cell processes, such as regulation of transcription, ion transport, cell adhesion, signal transduction, nervous system development, oxidation reduction, protein transport, RNA splicing and synaptic transmission. In the brains of naturally-occurring or experimental animal and human TSEs, as well as in some prion infected cell lines $(5,6,15-17)$, abnormal alterations in ion transportation, transcription, cell adhesion, signal transduction and synaptic transmission have been repeatedly observed. Numerous differentially expressed genes involved in different cell processes or networks in brain tissues of this G114V gCJD patient reflect an extensive brain dysfunction at the final period of the disease.

Based on the classification of the KEGG database, 169 different pathways were significantly altered in the brain of the patient with G114V gCJD. Most of the differentially expressed genes in the 10 most significantly altered pathways were downregulated, revealing a deeply suppressed expression status of the relevant functions. Two metabolic pathways, oxidative phosphorylation and purine metabolism, were markedly repressed in our study. In the oxidative phosphorylation pathway, the expression of several key elements, such as NADH dehydrogenase, succinate dehydrogenase, cytochrome $c$ reductase, 
Alzheimer's disease

\begin{tabular}{|l|l}
7.42 & ITPR1 \\
7.34 & GRIN2D \\
6.57 & NDUFS8 \\
0.17 & UQCRQ \\
0.17 & NDUFB9 \\
0.16 & NDUFAB1 \\
0.16 & PSEN1 \\
0.15 & ATP5C1 \\
0.15 & NDUFV2 \\
0.15 & MAPT \\
0.15 & COX7C \\
0.14 & COX5A \\
0.14 & NDUFB6 \\
0.14 & APOE \\
0.14 & APP \\
0.13 & MAPK1 \\
0.13 & ATP5A1 \\
0.13 & PSENEN \\
0.13 & UQCRC1 \\
0.12 & PSEN1 \\
0.12 & ITPR1 \\
0.12 & SNCA \\
0.12 & NDUFB7 \\
0.12 & NDUFS1 \\
0.12 & ATP5C1 \\
0.11 & ATP2A2 \\
0.11 & NDUFC2 \\
0.11 & SDHB \\
0.11 & UQCRC2 \\
0.11 & NDUFB10 \\
0.1 & ATP5B \\
0.09 & PPP3CB \\
0.09 & PPP3CA \\
0.09 & CDK5 \\
0.08 & UQCRC2 \\
0.07 & CDK5R1 \\
0.06 & PPP3R1 \\
0.05 & SNCA \\
0.03 & GRIN2A \\
\hline & \\
\hline
\end{tabular}

138019

Al524330

AK002110

NM_014402

AF261090

NM 005003

NM_007319

BC000931

NM_021074

NM 016835

AA382702

NM_004255

NM_002493

N33009

X06989

AA195999

Al587323

NM_018468

NM_003365

NM_007318

U23850

NM_000345

NM_004146

Al808395

NM_005174

M23114

NM_004549

NM_003000

AV727381

AF044954

NM_001686

M29550

AL353950

NM 004935

NM_003366

AL567411

NM_000945

BG260394

T65537

inositol 1,4,5-triphosphate receptor, type

glutamate receptor, ionotropic, $\mathrm{N}$-methyl $\mathrm{D}$-aspartate $2 \mathrm{D}$

NADH dehydrogenase (ubiquinone) Fe-S protein $8,23 \mathrm{kDa}$ (NADH-coenzyme $\mathrm{Q}$ reductase)

A

NADH dehydrogenase (ubiquinone) 1 beta subcomplex, $9,22 \mathrm{kDa}$

NADH dehydrogenase (ubiquinone) 1 , alpha/beta subcomplex, 1, $8 \mathrm{kDa}$

presenilin 1

ATP synthase, $\mathrm{H}+$ transporting, mitochondrial F1 complex, gamma polypeptide

$\mathrm{NADH}$ dehydrogenase (ubiquinone) flavoprotein $2,24 \mathrm{kDa}$

microtubule-associated protein tau

cytochrome c oxidase subunit VIlc

cytochrome coxidase subunit $\mathrm{Va}$

NADH dehydrogenase (ubiquinone) 1 beta subcomplex, 6, $17 \mathrm{kDa}$

apolipoprotein

amyloid beta (A4) precursor protein

mitogen-activated protein kinase 1

ATP synthase, $\mathrm{H}+$ transporting mitochondrial F1 complex, alpha subunit 1, cardiac muscle

presenilin enhancer 2 homolog (C. elegans)

ubiquinol-cytochrome $\mathrm{c}$ reductase core protein I

presenilin 1

inositol 1,4,5-triphosphate receptor, type 1

synuclein, alpha (non A4 component of amyloid precursor)

NADH dehydrogenase (ubiquinone) 1 beta subcomplex, $7,18 \mathrm{kDa}$

$\mathrm{NADH}$ dehydrogenase (ubiquinone) $\mathrm{Fe}-\mathrm{S}$ protein $1,75 \mathrm{kDa}$ (NADH-coenzyme $\mathrm{Q}$ reductase)

ATP synthase, $\mathrm{H}+$ transporting, mitochondrial F1 complex, gamma polypeptide 1

ATPase, $\mathrm{Ca}++$ transporting, cardiac muscle, slow twitch 2

NADH dehydrogenase (ubiquinone) 1, subcomplex unknown, 2, $14.5 \mathrm{kDa}$

succinate dehydrogenase complex, subunit $B$, iron sulfur (lp)

ubiquinol-cytochrome $\mathrm{c}$ reductase core protein II

NADH dehydrogenase (ubiquinone) 1 beta subcomplex, 10, $22 \mathrm{kDa}$

ATP synthase, $\mathrm{H}+$ transporting, mitochondrial F1 complex, beta polypeptide

protein phosphatase 3 (formerly $2 \mathrm{~B}$ ), catalytic subunit, beta isoform

protein phosphatase 3 (formerly $2 \mathrm{~B}$ ), catalytic subunit, alpha isoform

cyclin-dependent kinase 5

ubiquinol-cytochrome $\mathrm{c}$ reductase core protein II

cyclin-dependent kinase 5 , regulatory subunit 1 (p35)

protein phosphatase 3 (formerly $2 B$ ), regulatory subunit $B$, alpha isoform

synuclein, alpha (non A4 component of amyloid precursor)

glutamate receptor, ionotropic, $\mathrm{N}$-methyl $\mathrm{D}$-aspartate $2 \mathrm{~A}$

Oxidative phosphorylation

\begin{tabular}{|c|c|c|c|}
\hline 6.57 & NDUFSB & AK002110 & $\mathrm{NADH}$ dehydrogenase (ubiquinone) $\mathrm{Fe}-\mathrm{S}$ protein $8,23 \mathrm{kDa}$ ( $\mathrm{NADH}$-coenzyme $\mathrm{Q}$ reductase) \\
\hline 0.17 & ATP6V0E1 & NM_003945 & ATPase, $\mathrm{H}+$ transporting, lysosomal $9 \mathrm{kDa}$, V0 subunit e1 \\
\hline 0.17 & UQCRQ & NM_014402 & ubiquinol-cytochrome c reductase, complex III subunit VII, 9.5 kDa \\
\hline 0.17 & NDUFB9 & AF261090 & $\mathrm{NADH}$ dehydrogenase (ubiquinone) 1 beta subcomplex, $9,22 \mathrm{kDa}$ \\
\hline 0.17 & ATP6V1C1 & AW241758 & ATPase, $\mathrm{H}+$ transporting, lysosomal $42 \mathrm{kDa}, \mathrm{V} 1$ subunit $\mathrm{C} 1$ \\
\hline 0.16 & FUT5 /// NDUFA11 & BE741920 & fucosyltransferase 5 (alpha $(1,3)$ fucosyltransferase) /// NADH dehydrogenase (ubiquinone) \\
\hline 0.16 & NDUFAB1 & NM_005003 & NADH dehydrogenase (ubiquinone) 1, alpha/beta subcomplex, 1, $8 \mathrm{kDa}$ \\
\hline 0.16 & PPA1 & NM_021129 & pyrophosphatase (inorganic) 1 \\
\hline 0.15 & ATP5C1 & BC000931 & ATP synthase, $\mathrm{H}+$ transporting, mitochondrial F1 complex, gamma polypeptide 1 \\
\hline 0.15 & NDUFV2 & NM_021074 & $\mathrm{NADH}$ dehydrogenase (ubiquinone) flavoprotein $2,24 \mathrm{kDa}$ \\
\hline 0.15 & $\operatorname{cox} 7 \mathrm{C}$ & AA382702 & cytochrome c oxidase subunit Vllc \\
\hline 0.14 & COX5A & NM_004255 & cytochrome $\mathrm{c}$ oxidase subunit $\mathrm{Va}$ \\
\hline 0.14 & NDUFB6 & NM_002493 & NADH dehydrogenase (ubiquinone) 1 beta subcomplex, 6, $17 \mathrm{kDa}$ \\
\hline 0.14 & CoX17 & NM_005694 & COX17 cytochrome c oxidase assembly homolog (S. cerevisiae) \\
\hline 0.13 & ATP5A1 & Al587323 & ATP synthase, $\mathrm{H}+$ transporting, mitochondrial $\mathrm{F} 1$ complex, alpha subunit 1 , cardiac muscle \\
\hline 0.13 & ATP6V1C1 & NM_001695 & ATPase, $\mathrm{H}+$ transporting, lysosomal $42 \mathrm{kDa}, \mathrm{V} 1$ subunit $\mathrm{C} 1$ \\
\hline 0.13 & UQCRC1 & NM_003365 & ubiquinol-cytochrome $\mathrm{c}$ reductase core protein I \\
\hline 0.12 & NDUFB7 & NM_004146 & $\mathrm{NADH}$ dehydrogenase (ubiquinone) 1 beta subcomplex, $7,18 \mathrm{kDa}$ \\
\hline 0.12 & NDUFS1 & Al808395 & $\mathrm{NADH}$ dehydrogenase (ubiquinone) Fe-S protein $1,75 \mathrm{kDa}$ ( $\mathrm{NADH}$-coenzyme $\mathrm{Q}$ reductase) \\
\hline 0.12 & ATP5C1 & NM_005174 & ATP synthase, $\mathrm{H}+$ transporting, mitochondrial F1 complex, gamma polypeptide 1 \\
\hline 0.11 & ATP6V1E1 & $\mathrm{BC} 004443$ & ATPase, $\mathrm{H}+$ transporting, lysosomal $31 \mathrm{kDa}, \mathrm{V} 1$ subunit $\mathrm{E} 1$ \\
\hline 0.11 & NDUFC2 & NM_004549 & NADH dehydrogenase (ubiquinone) 1, subcomplex unknown, 2, $14.5 \mathrm{kDa}$ \\
\hline 0.11 & PPA2 & AF086012 & Pyrophosphatase (inorganic) 2 \\
\hline 0.11 & SDHB & NM_003000 & succinate dehydrogenase complex, subunit B, iron sulfur (Ip) \\
\hline 0.11 & UQCRC2 & AV727381 & ubiquinol-cytochrome c reductase core protein II \\
\hline 0.11 & NDUFB10 & AF044954 & $\mathrm{NADH}$ dehydrogenase (ubiquinone) 1 beta subcomplex, 10, $22 \mathrm{kDa}$ \\
\hline 0.10 & ATP5B & NM_001686 & ATP synthase, $\mathrm{H}+$ transporting, mitochondrial F1 complex, beta polypeptide \\
\hline 0.09 & cox11 & Al $3 \overline{7} 6724$ & coX11 homolog, cytochrome c oxidase assembly protein (yeast) \\
\hline 0.08 & UQCRC2 & NM_003366 & ubiquinol-cytochrome $\mathrm{c}$ reductase core protein II \\
\hline 0.07 & ATP6V1H & AF112204 & ATPase, $\mathrm{H}+$ transporting, lysosomal $50 / 57 \mathrm{kDa}, \mathrm{V} 1$ subunit $\mathrm{H}$ \\
\hline 0.05 & ATP6V1A & NM_001690 & ATPase, $\mathrm{H}+$ transporting, lysosomal $70 \mathrm{kDa}, \mathrm{V} 1$ subunit $\mathrm{A}$ \\
\hline 0.05 & ATP6V1A & AF113129 & ATPase, $\mathrm{H}+$ transporting, lysosomal $70 \mathrm{kDa}, \mathrm{V} 1$ subunit $\mathrm{A}$ \\
\hline 0.04 & ATP6V1G2 & BF340635 & ATPase, $\mathrm{H}+$ transporting, lysosomal $13 \mathrm{kDa}, \mathrm{V} 1$ subunit $\mathrm{G} 2$ \\
\hline 0.03 & ATP6V1B2 & NM_001693 & ATPase, $\mathrm{H}+$ transporting, lysosomal $56 / 58 \mathrm{kDa}, \mathrm{V} 1$ subunit $\mathrm{B} 2$ \\
\hline
\end{tabular}

Figure 2. The 10 most altered pathways and the differentially expressed genes in them. The red color represents the upregulated genes and the green indicates downregulated ones. The gene symbols, RefSeq transcript ID, and gene titles of differentially expressed genes in each pathway are listed on the right. The altered ratios corresponding to various genes involved in pathways are indicated on the left.

cytochrome $c$ oxidase and F-type ATPase were decreased. This result is in accordance with previous studies by both microarray (5) and proteomics (18), reflecting a complete failure of mitochondria. Purine metabolism includes the biological synthesis, degradation and salvation of purines, an essential component of nucleotides (19). Abnormality in this pathway has not previously been observed in the prion-infected cells, or human and animal TSEs. Besides, the pathway of cellular proteasome in the brain of this gCJD case is significantly involved, in which various proteasome subunits are downregulated. The dysfunc- 
Parkinson's disease

\begin{tabular}{|l|l|}
\hline 6.57 & NDUFS8 \\
\hline 0.17 & PPID \\
0.17 & UQCRQ \\
0.17 & NDUFB9 \\
0.16 & NDUFAB1 \\
0.15 & ATP5C1 \\
0.15 & NDUFV2 \\
0.15 & UBE2G1 \\
0.15 & COX7C \\
0.14 & COX5A \\
0.14 & NDUFB6 \\
0.14 & HTRA2 \\
0.13 & ATP5A1 \\
0.13 & UQCRC1 \\
0.12 & UBE2L3 \\
0.12 & SLC25A4 \\
0.12 & SNCA \\
0.12 & NDUFB7 \\
0.12 & ATP5C1 \\
0.11 & NDUFC2 \\
0.11 & SDHB \\
0.11 & UQCRC2 \\
0.11 & NDUFB10 \\
0.10 & ATP5B \\
0.10 & VDAC3 \\
0.09 & UBE2G1 \\
0.08 & VDAC1 \\
0.08 & UQCRC2 \\
0.05 & GPR37 \\
0.05 & SNCA \\
0.02 & UCHL1 \\
\hline
\end{tabular}

AKO02110

Al014573

NM_014402

AF261090

NM 005003

BC000931

NM_021074

AW299555

AA382702

NM_004255

NM_002493

NM_013247

Al58 $\overline{8} 7323$

NM 003365

BG531983

NM 001151

NM_000345

NM 004146

NM_005174

NM 004549

NM_003000

AF044954

NM_001686

U90943

BC002775

AL515918

NM_003366

U87460

BG260394

NM_004181
$\mathrm{NADH}$ dehydrogenase (ubiquinone) Fe-S protein $8,23 \mathrm{kDa}$ (NADH-coenzyme $\mathrm{Q}$ reductase)

peptidylprolyl isomerase D

-cytochrome c reductase, complex III subunit VII, $9.5 \mathrm{kDa}$

(ubiquinone) 1 beta subcomplex $9,22 \mathrm{kDa}$

$\mathrm{NADH}$ dehydrogenase (ubiquinone) 1, alpha/beta subcomplex, 1, $8 \mathrm{kDa}$

ATP synthase, $\mathrm{H}+$ transporting, mitochondrial $\mathrm{F} 1$ complex, gamma polypeptide 1

$\mathrm{NADH}$ dehydrogenase (ubiquinone) flavoprotein $2,24 \mathrm{kDa}$

ubiquitin-conjugating enzyme E2G 1 (UBC7 homolog, yeast)

cytochrome c oxidase subunit VIlc

cytochrome coxidase subunit

NADH dehydrogenase (ubiquinone) 1 beta subcomplex, 6, $17 \mathrm{kDa}$

HtrA serine peptidase 2

ATP synthase, $\mathrm{H}+$ transporting, mitochondrial F1 complex, alpha subunit 1 , cardiac muscle ubiquinol-cytochrome $\mathrm{c}$ reductase core protein I

ubiquitin-conjugating enzyme E2L 3

solute carrier family 25 (mitochondrial carrier; adenine nucleotide translocator), member 4

synuclein, alpha (non A4 component of amyloid precursor)

$\mathrm{NADH}$ dehydrogenase (ubiquinone) 1 beta subcomplex, $7,18 \mathrm{kDa}$

ATP synthase, $\mathrm{H}+$ transporting, mitochondrial $\mathrm{F} 1$ complex, gamma polypeptide 1

$\mathrm{NADH}$ dehydrogenase (ubiquinone) 1 , subcomplex unknown, 2, $14.5 \mathrm{kDa}$

succinate dehydrogenase complex, subunit B, iron sulfur (lp)

ubiquinol-cytochrome $\mathrm{c}$ reductase core protein II

$\mathrm{NADH}$ dehydrogenase (ubiquinone) 1 beta subcomplex, 10, $22 \mathrm{kDa}$

synthase, $\mathrm{H}+$ transporting, mitochondrial $\mathrm{F} 1$ complex, beta polypeptide

voltage-dependent anion channel 3

ubiquitin-conjugating enzyme E2G 1 (UBC7 homolog, yeast)

voltage-dependent anion channel 1

ubiquinol-cytochrome $\mathrm{c}$ reductase core protein II

$\mathrm{G}$ protein-coupled receptor 37 (endothelin receptor type B-like)

synuclein, alpha (non A4 component of amyloid precursor)

ubiquitin carboxyl-terminal esterase L1 (ubiquitin thiolesterase)
Regulation of actin cytoskeleton

\begin{tabular}{|lll}
9.47 & PPP1R12A & BE737620 \\
6.17 & SOS2 & BF692958 \\
6.05 & APC & M74088 \\
0.16 & PTK2 & AA912743 \\
0.15 & TIAM2 & Al094945 \\
0.15 & ACTN2 & AU146889 \\
0.14 & PIP4K2C & NM_024779 \\
0.14 & ARPC2 & AF279893 \\
0.14 & RHOA & AF498970 \\
0.13 & MAPK1 & AA195999 \\
0.13 & WASL & BE504979 \\
0.13 & MYH10 & AK026977 \\
0.13 & FGF14 & BE549937 \\
0.13 & ARHGEF7 & Al040887 \\
0.13 & TIAM1 & U90902 \\
0.12 & CDC42 & N92917 \\
0.12 & CDC42 & N92917 \\
0.12 & GSN & NM_000177 \\
0.11 & PIP5K1B & NM_003558 \\
0.11 & NCKAP1 & NM_013436 \\
0.11 & ARPC3 & AF004561 \\
0.11 & CFL1 & D00682 \\
0.10 & ARPC1A & NM_006409 \\
0.10 & WASL & AL523820 \\
0.10 & WASF1 & NM_003931 \\
0.10 & FGFR2 & NM_022975 \\
0.09 & FGF14 & NM_004115 \\
0.09 & MAP2K1 & Al571419 \\
0.09 & ITGAM & NM_000632 \\
0.09 & ARPC5L & AU158936 \\
0.07 & RDX & Al051769 \\
0.07 & PAK1 & AU147145 \\
0.06 & ACTN2 & H16245 \\
0.05 & CDC42 & R37664 \\
0.04 & CDC42 & M35543 \\
0.03 & FGF13 & NM_004114 \\
0.03 & ARHGEF7 & AI990366 \\
& & \\
\hline
\end{tabular}

protein phosphatase 1, regulatory (inhibitor) subunit 12A

son of sevenless homolog 2 (Drosophila)

adenomatous polyposis coli

PTK2 protein tyrosine kinase 2

T-cell lymphoma invasion and metastasis 2

actinin, alpha 2

phosphatidylinositol-5-phosphate 4-kinase, type II, gamma

actin related protein $2 / 3$ complex, subunit $2,34 \mathrm{kDa}$

ras homolog gene family, member $A$

mitogen-activated protein kinase

Wiskott-Aldrich syndrome-like

myosin, heavy chain 10 , non-muscle

fibroblast growth factor 14

Rho guanine nucleotide exchange factor (GEF) 7

T-cell lymphoma invasion and metastasis 1

Cell division cycle 42 (GTP binding protein, $25 \mathrm{kDa}$ )

Cell division cycle 42 (GTP binding protein, $25 \mathrm{kDa}$ )

gelsolin (amyloidosis, Finnish type)

phosphatidylinositol-4-phosphate 5-kinase, type I, beta

NCK-associated protein 1

actin related protein $2 / 3$ complex, subunit $3,21 \mathrm{kDa}$

cofilin 1 (non-muscle)

actin related protein $2 / 3$ complex subunit $1 \mathrm{~A}, 41 \mathrm{kDa}$

Wiskott-Aldrich syndrome-like

WAS protein family, member 1

fibroblast growth factor receptor 2

fibroblast growth factor 14

mitogen-activated protein kinase kinase 1

integrin, alpha M (complement component 3 receptor 3 subunit)

actin related protein $2 / 3$ complex, subunit 5-like

radixin

p21 protein (Cdc42/Rac)-activated kinase 1

actinin, alpha 2

cell division cycle 42 (GTP binding protein, $25 \mathrm{kDa}$ )

cell division cycle 42 (GTP binding protein, $25 \mathrm{kDa}$ )

fibroblast growth factor 13

Rho guanine nucleotide exchange factor (GEF) 7

Figure 2. Continued.

tion of the cellular proteasome system is often noticed in several neurodegenerative disorders (18), including prion disease (20). The disability of protein degradation, especially in clearance of misfolded protein, may contribute to the accumulation of $\mathrm{PrP}^{\mathrm{Sc}}$ in brain tissues.

It has been repeatedly observed that the cytoskeleton and microtubule are severely destroyed in the brain of prion disease (21-23). In our study, the pathway of regulation of actin cytoskeleton and the pathway involved in the expressions of cell structure proteins, such as CDC42 and tubulin, were clearly suppressed. Reduction of expression levels of those genes results in rearrangement of the cytoskeleton, disruption of barrier function and an increase in monolayer permeability.

The MAPK cascade is a highly conserved pathway involved in various cellular functions, including cell proliferation, differentiation and migration. Our microarray experiment illustrated the increased expression of p38 MAP kinase and nuclear factor $-\kappa \mathrm{B}(\mathrm{NF}-\kappa \mathrm{B})$ in the brain of gCJD. The increase 


\begin{tabular}{|c|c|c|c|}
\hline \multicolumn{4}{|c|}{ Patnogenic Escherichla coll iniection } \\
\hline 0.16 & TUBB2C & BC004188 & tubulin, beta $2 \mathrm{C}$ \\
\hline 0.16 & TUBA1B & BC006481 & tubulin, alpha $1 \mathrm{~b}$ \\
\hline 0.16 & TUBA1C & BC005946 & tubulin, alpha 1c \\
\hline 0.15 & TUBA1B & BE300252 & tubulin, alpha $1 \mathrm{~b}$ \\
\hline 0.15 & TUBA1B & AL581768 & tubulin, alpha $1 \mathrm{~b}$ \\
\hline 0.15 & TUBA1C & BC004949 & tubulin, alpha 1c \\
\hline 0.15 & TUBA1B & BC006379 & tubulin, alpha $1 \mathrm{~b}$ \\
\hline 0.15 & CTNNB1 & AB062292 & catenin (cadherin-associated protein), beta 1, $88 \mathrm{kDa}$ \\
\hline 0.13 & TUBB2A & NM_001069 & tubulin, beta $2 \mathrm{~A}$ \\
\hline 0.13 & WASL & BE504979 & Wiskott-Aldrich syndrome-like \\
\hline 0.13 & TUBB2A /// TUBB2B & BF971587 & tubulin, beta $2 \mathrm{~A} / / /$ tubulin, beta $2 \mathrm{~B}$ \\
\hline 0.13 & TUBB & $\mathrm{BC} 001002$ & tubulin, beta \\
\hline $\begin{array}{l}0.12 \\
0.10\end{array}$ & $\begin{array}{l}\text { CDC42 } \\
\text { TUBB4 }\end{array}$ & $\begin{array}{l}\text { N92917 } \\
\text { AL567012 }\end{array}$ & $\begin{array}{l}\text { Cell division cycle } 42 \text { (GTP binding protein, } 25 \mathrm{kDa} \text { ) } \\
\text { tubulin, beta } 4\end{array}$ \\
\hline 0.10 & WASL & AL523820 & Wiskott-Aldrich syndrome-like \\
\hline 0.09 & ARPC5L & AU158936 & actin related protein $2 / 3$ complex, subunit 5 -like \\
\hline 0.09 & TUBB & BC005838 & tubulin, beta \\
\hline 0.09 & TUBA3C & L11645 & tubulin, alpha $3 c$ \\
\hline 0.08 & TUBB & AF141349 & tubulin, beta \\
\hline 0.06 & YWHAZ & NM_003406 & tyrosine 3-monooxygenase/tryptophan 5-monooxygenase activation protein, zeta polypeptide \\
\hline 0.06 & YWHAZ & $\mathrm{BC} 003623$ & tyrosine 3-monooxygenase/tryptophan 5-monooxygenase activation protein, zeta polypeptide \\
\hline 0.06 & TUBA4A & AL565074 & tubulin, alpha $4 a$ \\
\hline 0.06 & TUBA3D & K03460 & tubulin, alpha $3 \mathrm{~d}$ \\
\hline $\begin{array}{l}0.05 \\
0.04\end{array}$ & $\begin{array}{l}\text { CDC42 } \\
\text { CDC42 }\end{array}$ & $\begin{array}{l}\text { R37664 } \\
\text { M35543 }\end{array}$ & $\begin{array}{l}\text { cell division cycle } 42 \text { (GTP binding protein, } 25 \mathrm{kDa} \text { ) } \\
\text { cell division cycle } 42 \text { (GTP binding protein, } 25 \mathrm{kDa} \text { ) }\end{array}$ \\
\hline
\end{tabular}

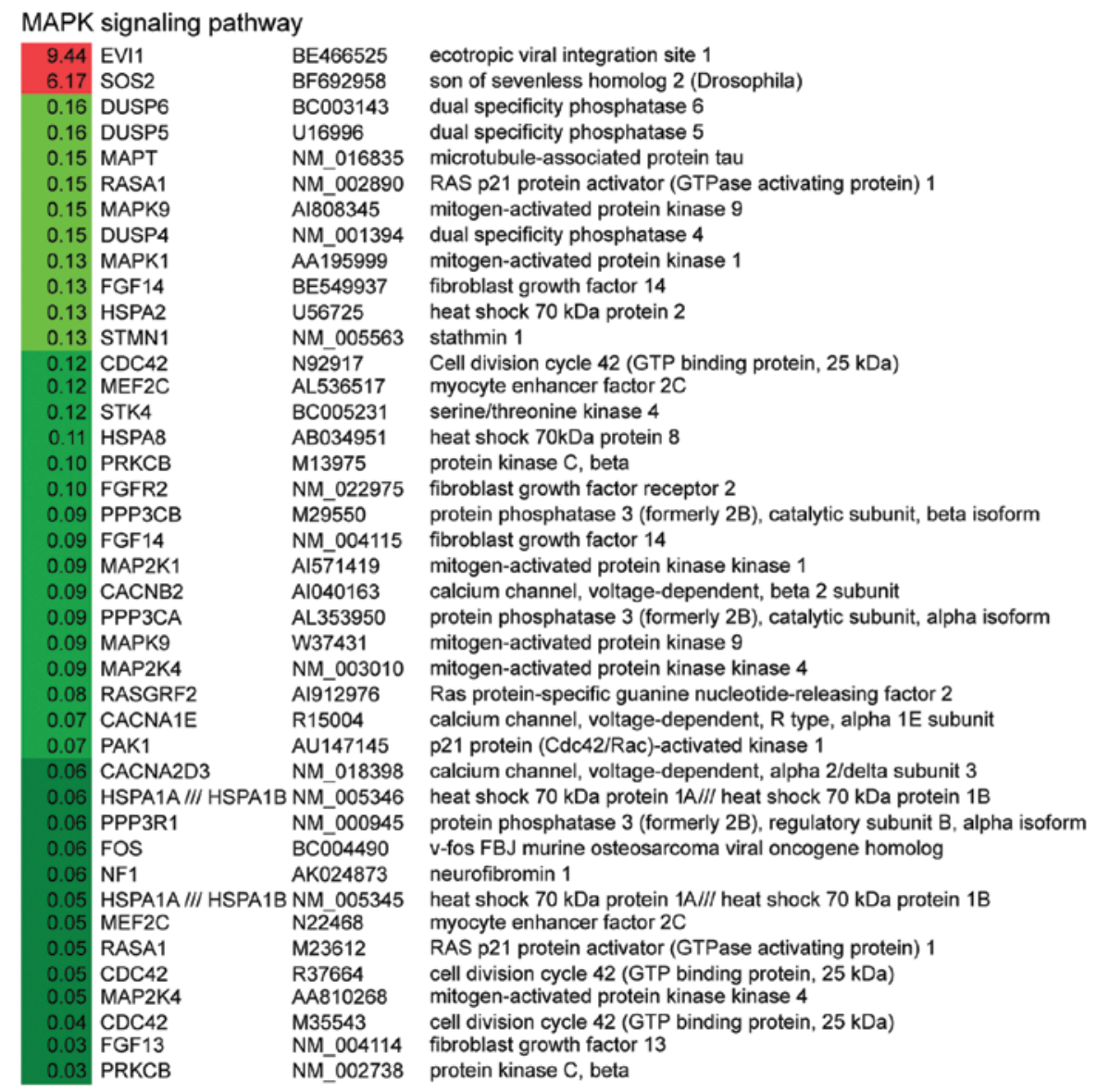

Figure 2. Continued.

of those two factors has been reported in cells treated with the peptide PrP106-126. PrP106-126 has been demonstrated to activate $\mathrm{p} 38$ MAP kinase in human microglia accompanied by upregulation of NF- $\mathrm{NB}$ (24), and to induce a p38 MAP kinase-dependent apoptosis in SH-SY5Y neuroblastoma cells independently from the amyloid fibril formation (25). The decrease of ERK in our microarray is also in line with the observation that PrP fragment (aa 90-231) activates p38 MAP kinase by inhibiting the activation of extracellular-regulated kinases 1/2 (ERK1/2), followed by the caspase-3-dependent cell apoptosis in SH-SY5Y cells (26).

Genes involved in axon guidance and gap junctions, which are critical for cell communication and cell development, are rarely investigated in prion diseases. Axon guidance is a subfield of neural development concerning the process by which neurons send out axons to reach the correct targets. Its role in prion disease is rarely described, until recently a group performed systematical analyses on the gene changes 


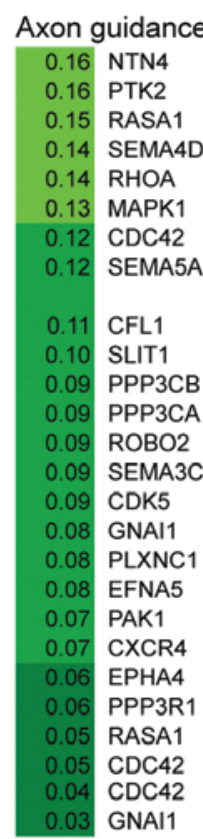

\begin{tabular}{|c|c|c|}
\hline \multicolumn{3}{|c|}{ Gap junction } \\
\hline 9.27 & ADRB1 & NM_000684 \\
\hline 7.42 & ITPR1 & L38019 \\
\hline 6.17 & sos2 & BF692958 \\
\hline 0.16 & TUBB2C & BC004188 \\
\hline 0.16 & TUBA1B & BC006481 \\
\hline 0.16 & TUBA1C & BC005946 \\
\hline 0.15 & TUBA1B & BE300252 \\
\hline 0.15 & TUBA1B & AL581768 \\
\hline 0.15 & TUBA1C & BC004949 \\
\hline 0.15 & TUBA1B & BC006379 \\
\hline 0.13 & MAPK1 & AA195999 \\
\hline 0.13 & TUBB2A & NM_001069 \\
\hline 0.13 & TUBB2A /// TUBB2B & BF971587 \\
\hline 0.13 & GNAS & AA401492 \\
\hline 0.13 & TUBB & BC001002 \\
\hline 0.12 & ITPR1 & U23850 \\
\hline 0.10 & TUBB4 & AL567012 \\
\hline 0.10 & PRKCB & M13975 \\
\hline 0.09 & MAP2K1 & Al571419 \\
\hline 0.09 & TUBB & BC005838 \\
\hline 0.09 & GRM1 & NM_000838 \\
\hline 0.09 & TUBA3C & $\mathrm{L} 11645$ \\
\hline 0.08 & TUBB & AF141349 \\
\hline 0.06 & TUBA4A & AL565074 \\
\hline $\begin{array}{l}0.06 \\
0.05\end{array}$ & $\begin{array}{l}\text { TUBA3D } \\
\text { GUCY1B3 }\end{array}$ & $\begin{array}{l}\text { K03460 } \\
\text { W93728 }\end{array}$ \\
\hline 0.03 & GNAI1 & AL049933 \\
\hline 0.03 & PRKCB & NM_002738 \\
\hline
\end{tabular}

netrin 4

PTK2 protein tyrosine kinase 2

AA912743 RAS 21 protein activator (GTPase activating protein) 1

NM_006378 sema domain, immunoglobulin domain (lg), transmembrane domain (TM) and short cytoplasmic domain, (semaphorin) 4D

AF498970 ras homolog gene family, member $A$

AA195999 mitogen-activated protein kinase 1

N92917 Cell division cycle 42 (GTP binding protein, $25 \mathrm{kDa}$ )

BG109855 sema domain, seven thrombospondin repeats (type 1 and type 1-like), transmembrane domain and short cytoplasmic domain, (semaphorin) $5 \mathrm{~A}$

D00682 cofilin 1 (non-muscle)

AB011537 slit homolog 1 (Drosophila)

M29550 protein phosphatase 3 (formerly 2B), catalytic subunit, beta isoform

AL353950 protein phosphatase 3 (formerly 2B), catalytic subunit, alpha isoform

AB046788 roundabout, axon guidance receptor, homolog 2 (Drosophila)

NM_006379 sema domain, immunoglobulin domain (lg), short basic domain, secreted, (semaphorin) 3C

NM 004935 cyclin-dependent kinase 5

AU153866 guanine nucleotide binding protein ( $G$ protein), alpha inhibiting activity polypeptide 1

AF035307 plexin C1

AK025909 Ephrin-A5

AU147145 p21 protein (Cdc42/Rac)-activated kinase 1

AJ224869 chemokine (C-X-C motif) receptor 4

Al799018 EPH receptor A4

NM 000945 protein phosphatase 3 (formerly 2B), regulatory subunit B, alpha isoform

M23612 RAS p21 protein activator (GTPase activating protein) 1

R37664 cell division cycle 42 (GTP binding protein, $25 \mathrm{kDa}$ )

M35543 cell division cycle 42 (GTP binding protein, $25 \mathrm{kDa}$ )

AL049933 guanine nucleotide binding protein ( $G$ protein), alpha inhibiting activity polypeptide 1 adrenergic, beta-1-, receptor

inositol 1,4,5-triphosphate receptor, type 1

son of sevenless homolog 2 (Drosophila)

tubulin, beta $2 \mathrm{C}$

tubulin, alpha $1 \mathrm{~b}$

tubulin, alpha 1c

tubulin, alpha 1b

tubulin, alpha $1 \mathrm{~b}$

tubulin, alpha 1c

tubulin, alpha 1b

mitogen-activated protein kinase 1

tubulin, beta $2 A$

tubulin, beta $2 \mathrm{~A} / / /$ tubulin, beta $2 \mathrm{~B}$

GNAS complex locus

tubulin, beta

inositol 1,4,5-triphosphate receptor, type 1

tubulin, beta 4

protein kinase $\mathrm{C}$, beta

mitogen-activated protein kinase kinase 1

tubulin, beta

glutamate receptor, metabotropic 1

tubulin, alpha $3 c$

tubulin, beta

tubulin, alpha $4 a$

tubulin, alpha $3 d$

guanylate cyclase 1 , soluble, beta 3

guanine nucleotide binding protein ( $\mathrm{G}$ protein), alpha inhibiting activity polypeptide 1

protein kinase $\mathrm{C}$, beta

Figure 2. Continued.

in the brains of eight mouse adapted-prion strains throughout the progression of the diseases. Axon guidance disturbance was found in the mice with shorter incubation times (5). Gap junctions are involved in direct communication between the cytosolic compartments of adjacent cells. Apart from the changes of MAPK associated genes, some receptors of monoamines and other biogenic amine neurotransmitters, such as $\beta-1$ adrenergic receptor (ADRB1), dopamine receptor D2 (DRD2), 5-hydroxytryptamine (serotonin) receptor 2 (HTR2) and $\mathrm{mGluR}$ are suppressed, resulting in abnormal regulation of the expressions of the genes downstream and subsequently inducing the dysfunction of calcium signaling pathway and transportation of other biological masses.
The most significantly altered pathways in human diseases in the brain of the G114V gCJD patient are those of AD and $\mathrm{PD}$, strongly indicating that G114V gCJD shares the similar gene expression profiles as these two neurodegenerative diseases. Among these two pathways, cell death induced by changes of oxidative phosphorylation in the mitochondria is a critical factor for neuron loss in AD and PD $(18,27)$. In G114V gCJD, distinct impediment of oxidation phosphorylation is also observed. This includes abnormal phosphorylation, ATP depletion, collapse of mitochondrial membrane potential, increase of reactive oxygen species (ROS). Moreover, reduction of the expression of the relevant genes in this gCJD case highlight the presence of the similar ER stress-induced cell 


\begin{tabular}{|c|c|c|}
\hline \multicolumn{3}{|c|}{ Proteasome } \\
\hline 0.17 & PSMC3 & AL545523 \\
\hline 0.16 & PSMC2 & NM_002803 \\
\hline 0.15 & PSMA5 & NM_002790 \\
\hline 0.14 & PSMD8 & NM_002812 \\
\hline 0.13 & PSMD6 & NM_014814 \\
\hline 0.13 & PSMB4 & NM_002796 \\
\hline 0.13 & PSMB3 & NM_002795 \\
\hline 0.13 & PSMB6 & $\mathrm{BC} \overline{0} 00835$ \\
\hline 0.13 & PSMB2 & NM_002794 \\
\hline 0.12 & PSMB7 & NM_002799 \\
\hline 0.11 & PSMC4 & NM_006503 \\
\hline 0.11 & PSMA1 & M64992 \\
\hline 0.09 & PSMB1 & NM_002793 \\
\hline 0.09 & PSMA1 & NM_002786 \\
\hline 0.07 & PSMA1 & $\mathrm{BC} 05932$ \\
\hline 0.05 & PSMD12 & NM_002816 \\
\hline
\end{tabular}

proteasome (prosome, macropain) 26S subunit, ATPase, 3 proteasome (prosome, macropain) 26S subunit, ATPase, 2 proteasome (prosome, macropain) subunit, alpha type, 5 proteasome (prosome, macropain) 26S subunit, non-ATPase, 8 proteasome (prosome, macropain) 26S subunit, non-ATPase, 6 proteasome (prosome, macropain) subunit, beta type, 4 proteasome (prosome, macropain) subunit, beta type, 3 proteasome (prosome, macropain) subunit, beta type, 6 proteasome (prosome, macropain) subunit, beta type, 2 proteasome (prosome, macropain) subunit, beta type, 7 proteasome (prosome, macropain) 26S subunit, ATPase, 4 proteasome (prosome, macropain) subunit, alpha type, 1 proteasome (prosome, macropain) subunit, beta type, 1 proteasome (prosome, macropain) subunit, alpha type, 1 proteasome (prosome, macropain) subunit, alpha type, 1 proteasome (prosome, macropain) 26S subunit, non-ATPase, 12

\begin{tabular}{|r|l}
\hline Purine metabolism \\
\hline 0.17 & PRPS1 \\
0.16 & PAPSS1 \\
0.15 & PDE6D \\
0.15 & POLE3 \\
0.14 & POLR2E \\
0.14 & POLR2B \\
0.14 & POLR2K \\
0.13 & PRPS2 \\
0.12 & DCK \\
0.12 & POLR3K \\
0.12 & ENTPD3 \\
0.11 & PRPS1 \\
0.11 & ADSL \\
0.11 & DGUOK \\
0.10 & PDE10A \\
0.10 & ADSS \\
0.08 & PDE8B \\
0.07 & AK5 \\
0.06 & GDA \\
0.06 & NME1 \\
0.05 & PDE1A \\
0.05 & NME7 \\
0.05 & GUCY1B3 \\
0.04 & PRPS2 \\
0.04 & HPRT1 \\
\hline
\end{tabular}

\author{
NM_002764 \\ AF033026 \\ AJ001626 \\ BC004170 \\ Al554759 \\ BE614461 \\ NM_005034 \\ Al392908 \\ NM_000788 \\ NM_016310 \\ NM_001248 \\ BC001605 \\ AF067854 \\ NM 001929 \\ Al143879 \\ AA628948 \\ AB085825 \\ NM_012093 \\ AF019638 \\ NM_000269 \\ AW $\overline{6} 14381$ \\ Al094580 \\ W93728 \\ NM_002765 \\ NM_000194 \\ phosphoribosyl pyrophosphate synthetase 1 \\ 3'-phosphoadenosine 5'-phosphosulfate synthase 1 \\ phosphodiesterase 6D, cGMP-specific, rod, delta \\ polymerase (DNA directed), epsilon 3 ( $p 17$ subunit) \\ polymerase (RNA) II (DNA directed) polypeptide E, $25 \mathrm{kDa}$ \\ polymerase (RNA) II (DNA directed) polypeptide B, $140 \mathrm{kDa}$ \\ polymerase (RNA) II (DNA directed) polypeptide K, 7.0 kDa \\ Phosphoribosyl pyrophosphate synthetase 2 \\ deoxycytidine kinase \\ polymerase (RNA) III (DNA directed) polypeptide K, $12.3 \mathrm{kDa}$ \\ ectonucleoside triphosphate diphosphohydrolase 3 \\ phosphoribosyl pyrophosphate synthetase 1 \\ adenylosuccinate lyase \\ deoxyguanosine kinase \\ phosphodiesterase 10A \\ adenylosuccinate synthase \\ phosphodiesterase 8B \\ adenylate kinase 5 \\ guanine deaminase \\ non-metastatic cells 1, protein (NM23A) expressed in \\ phosphodiesterase $1 \mathrm{~A}$, calmodulin-dependent \\ non-metastatic cells 7 , protein expressed in (nucleoside-diphosphate kinase) \\ guanylate cyclase 1 , soluble, beta 3 \\ phosphoribosyl pyrophosphate synthetase 2 \\ hypoxanthine phosphoribosyltransferase 1
}

Figure 2. Continued.

death observed in AD and PD, and Fas-induced cell apoptosis observed in AD, which have also been described in BSE (28).

Aside from numerous genes downregulated in this gCJD case, there are several genes showing upregulation. Among the 12 upregulated genes in SCJD described previously (6), eight genes were increased in G114V gCJD, including RAB13 (RAB13, member RAS oncogene family), inositol 1,4,5-trisphosphate 3-kinase $\mathrm{B}$ (ITPKB) and transcriptional coactivator with PDZ-binding motif (TAZ) that are more than 2-fold increased, and GFAP, cysteine and glycine-rich protein 1 (CSRP1), tropomyosin 2 (TPM2), promoting factor 1 (PTN) and RNA binding motif, single stranded interacting protein 3 (RBMS3) that are more than 1.5-fold increased. The proteins of the Rab family regulate specific tethering/ docking of incoming vesicles to the correct target organelle (29), and they are involved in various biological processes, protein transport, small GTPase mediated signal transduction, vesicle-mediated transport, modification-dependent protein catabolism, ER to Golgi vesicle-mediated transport, endocytosis and some related regulation processes (12). Several Rab family members have been found to be associated with the $\mathrm{PrP}^{\mathrm{Sc}}$ propagation and accumulation in the prion-infected cells (30), as well as with the clinical manifestations (31). In line with the observation in SCJD, Rab genes are unregulated in the cerebral cortex of G114V gCJD. These phenomena illustrate the similarity of gene expression profiles between G114V gCJD and sCJD. More up and downregulated genes in G114V gCJD rely heavily on the usage of a relatively larger capacity gene chip in this study. In addition, a series of genes that appeared dozens of times increased both in microarray and qRT-PCR will provide useful insights to further explore potential biomarkers for the diagnosis of CJD.

\section{Acknowledgements}

We thank Dr Christopher J. Vavricka from the Institute of Microbiology, Chinese Academy of Sciences, Beijing, China, for kindly checking the manuscript. This study was supported by the Chinese National Natural Science Foundation Grants 30800975, 81101302 and 30800640, the National Basic Research Program of China (973 Program) (2007CB310505), the China Mega-Project for Infectious Disease (2009ZX10004101 and 2008ZX10004-008), and the SKLID Development Grant (2008SKLID102). 


\section{References}

1. Prusiner SB: Prions. Proc Natl Acad Sci USA 95: 13363-13383, 1998.

2. Colby DW and Prusiner SB: Prions. Cold Spring Harb Perspect Biol 3: a006833, 2011.

3. Pastore M, Chin SS, Bell KL, et al: Creutzfeldt-Jakob disease (CJD) with a mutation at codon 148 of prion protein gene: relationship with sporadic CJD. Am J Pathol 167: 1729-1738, 2005.

4. Collins S, McLean CA and Masters CL: Gerstmann-StrausslerScheinker syndrome, fatal familial insomnia, and kuru: a review of these less common human transmissible spongiform encephalopathies. J Clin Neurosci 8: 387-397, 2001.

5. Hwang D, Lee IY, Yoo H, et al: A systems approach to prion disease. Mol Syst Biol 5: 252, 2009.

6. Xiang W, Windl O, Westner IM, et al: Cerebral gene expression profiles in sporadic Creutzfeldt-Jakob disease. Ann Neurol 58 242-257, 2005

7. Ye J, Han J, Shi Q, et al: Human prion disease with a G114V mutation and epidemiological studies in a Chinese family: a case series. J Med Case Rep 2: 331, 2008.

8. Shi Q, Zhang BY, Gao C, et al: The diversities of $\operatorname{PrP}(\mathrm{Sc})$ distributions and pathologic changes in various brain regions from a Chinese patient with G114V genetic CJD. Neuropathology 32: 51-59, 2012.

9. Camon E, Magrane M, Barrell D, et al: The Gene Ontology Annotation (GOA) project: implementation of GO in SWISSPROT, TrEMBL, and InterPro. Genome Res 13: 662-672, 2003.

10. NCBI GEO Profiles: National Center for Biotechnology Information, US National Library of Medicine, Bethesda, MD http://www.ncbi.nlm.nih.gov/geo.

11. Mukherjee A and Soto C: Role of calcineurin in neurodegeneration produced by misfolded proteins and endoplasmic reticulum stress. Curr Opin Cell Biol 23: 223-230, 2011.

12. KEGG: Kyoto Encyclopedia of Genes and Genomes. http://www. genome.jp/kegg/.

13. Rodriguez MM, Peoc'h K, Haik S, et al: A novel mutation $(\mathrm{G} 114 \mathrm{~V})$ in the prion protein gene in a family with inherited prion disease. Neurology 64: 1455-1457, 2005.

14. Kordek R, Liberski PP, Yanagihara R, Isaacson S and Gajdusek DC: Molecular analysis of prion protein (PrP) and glial fibrillary acidic protein (GFAP) transcripts in experimental Creutzfeldt-Jakob disease in mice. Acta Neurobiol Exp 57: 85-90, 1997.

15. Tang Y, Xiang W, Hawkins SA, Kretzschmar HA and Windl O: Transcriptional changes in the brains of cattle orally infected with the bovine spongiform encephalopathy agent precede detection of infectivity. J Virol 83: 9464-9473, 2009.

16. Martinez $\mathrm{T}$ and Pascual A: Identification of genes differentially expressed in SH-SY5Y neuroblastoma cells exposed to the prion peptide 106-126. Eur J Neurosci 26: 51-59, 2007.
17. Xiang W, Windl O, Wunsch G, et al: Identification of differentially expressed genes in scrapie-infected mouse brains by using global gene expression technology. J Virol 78: 1105111060, 2004

18. Zabel C, Nguyen HP, Hin SC, Hartl D, Mao L and Klose J: Proteasome and oxidative phoshorylation changes may explain why aging is a risk factor for neurodegenerative disorders. J Proteomics 73: 2230-2238, 2010.

19. Wikipedia website: http://en.wikipedia.org/wiki/Purine_metabolism.

20. Deriziotis $P$ and Tabrizi SJ: Prions and the proteasome. Biochim Biophys Acta 1782: 713-722, 2008

21. Li XL, Wang GR, Jing YY, et al: Cytosolic PrP induces apoptosis of cell by disrupting microtubule assembly. J Mol Neurosci 43: 316-325, 2011.

22. Nieznanski K, Podlubnaya ZA and Nieznanska H: Prion protein inhibits microtubule assembly by inducing tubulin oligomerization. Biochem Biophys Res Commun 349: 391-399, 2006.

23. Osiecka KM, Nieznanska H, Skowronek KJ, Karolczak J, Schneider G and Nieznanski K: Prion protein region 23-32 interacts with tubulin and inhibits microtubule assembly. Proteins 77: 279-296, 2009.

24. Fabrizi C, Silei V, Menegazzi M, et al: The stimulation of inducible nitric-oxide synthase by the prion protein fragment 106-126 in human microglia is tumor necrosis factor-alphadependent and involves p38 mitogen-activated protein kinase. J Biol Chem 276: 25692-25696, 2001.

25. Corsaro A, Thellung S, Villa V, et al: Prion protein fragment 106-126 induces a p38 MAP kinase-dependent apoptosis in SH-SY5Y neuroblastoma cells independently from the amyloid fibril formation. Ann NY Acad Sci 1010: 610-622, 2003.

26. Corsaro A, Thellung S, Chiovitti K, et al: Dual modulation of ERK1/2 and p38 MAP kinase activities induced by minocycline reverses the neurotoxic effects of the prion protein fragment 90-231. Neurotox Res 15: 138-154, 2009.

27. Higgins GC, Beart PM, Shin YS, Chen MJ, Cheung NS and Nagley P: Oxidative stress: emerging mitochondrial and cellular themes and variations in neuronal injury. J Alzheimers Dis 20 (Suppl 2): S453-S473, 2010

28. Tang Y, Xiang W, Terry L, Kretzschmar HA and Windl O: Transcriptional analysis implicates endoplasmic reticulum stress in bovine spongiform encephalopathy. PLoS One 5: e14207, 2010

29. Zerial $\mathrm{M}$ and McBride $\mathrm{H}$ : Rab proteins as membrane organizers. Nat Rev Mol Cell Biol 2: 107-117, 2001.

30. Gilch S, Bach C, Lutzny G, Vorberg I and Schatzl HM: Inhibition of cholesterol recycling impairs cellular $\mathrm{PrP}(\mathrm{Sc})$ propagation. Cell Mol Life Sci 66: 3979-3991, 2009.

31. Ermolayev V, Cathomen T, Merk J, et al: Impaired axonal transport in motor neurons correlates with clinical prion disease. PLoS Pathog 5: e1000558, 2009. 